\title{
Pituitary surgery and volumetric assessment of extent of resection: a paradigm shift in the use of intraoperative magnetic resonance imaging
}

\author{
Carlo Serra, MD, ${ }^{1}$ Jan-Karl Burkhardt, MD, ${ }^{1}$ Giuseppe Esposito, MD, PhD, ${ }^{1}$ Oliver Bozinov, MD,1 \\ Athina Pangalu, MD, ${ }^{2}$ Antonios Valavanis, MD, ${ }^{2}$ David Holzmann, MD, ${ }^{3}$ Christoph Schmid, MD, ${ }^{4}$ \\ and Luca Regli, MD'
}

Departments of ${ }^{1}$ Neurosurgery, ${ }^{2}$ Neuroradiology, ${ }^{3}$ Otorhinolaryngology, Head and Neck Surgery, and ${ }^{4}$ Endocrinology and Diabetes, University Hospital of Zürich, University of Zürich, Switzerland

\begin{abstract}
OBJECTIVE The aim of this study was to quantitatively assess the role of intraoperative high-field 3-T MRI (3T-iMRI) in improving the gross-total resection (GTR) rate and the extent of resection (EOR) in endoscopic transsphenoidal surgery (TSS) for pituitary adenomas.

METHODS Radiological and clinical data from a prospective database were retrospectively analyzed. Volumetric measurements of adenoma volumes pre-, intraoperatively, and 3 months postoperatively were performed in a consecutive series of patients who had undergone endoscopic TSS. The quantitative contribution of 3T-iMRI was measured as a percentage of the additional rate of GTR and of the EOR achieved after 3T-iMRI.

RESULTS The cohort consisted of 50 patients (51 operations) harboring 33 nonfunctioning and 18 functioning pituitary adenomas. Mean adenoma diameter and volume were $21.1 \mathrm{~mm}$ (range $5-47 \mathrm{~mm}$ ) and $5.23 \mathrm{~cm}^{3}$ (range $0.09-22.14 \mathrm{~cm}^{3}$ ), respectively. According to Knosp's classification, 10 cases were Grade 0; 8, Grade 1; 17, Grade 2; 12, Grade 3; and 4, Grade 4. Gross-total resection was the surgical goal (targeted [t]GTR) in 34 of 51 operations and was initially achieved in $16(47 \%)$ of 34 at $3 \mathrm{~T}-\mathrm{iMRI}$ and in $30(88 \%)$ of 34 cases after further resection. In this subgroup, the EOR increased from $91 \%$ at 3 T-iMRI to $99 \%$ at the 3-month MRI $(p<0.05)$. In the 17 cases in which subtotal resection (STR) had been planned (tSTR), the EOR increased from $79 \%$ to $86 \%(p<0.05)$ and GTR could be achieved in 1 case. Intrasellar remnants were present in 20 of 51 procedures at 3T-iMRI and in only $5(10 \%)$ of 51 procedures after further resection (median volume $\left.0.15 \mathrm{~cm}^{3}\right)$. Overall, the use of 3 T-iMRI led to further resection in $27(53 \%)$ of 51 procedures and permitted GTR in 15 (56\%) of these 27 procedures; thus, the GTR rate in the entire cohort increased from $31 \%$ (16 of 51 ) to $61 \%$ (31 of 51 ) and the EOR increased from $87 \%$ to $95 \%(p<0.05)$.

CONCLUSIONS The use of high-definition 3T-iMRI allowed precise visualization and quantification of adenoma remnant volume. It helped to increase GTR and EOR rates in both tGTR and ISTR patient groups. Moreover, it helped to achieve low rates of intrasellar remnants. These data support the use of 3T-iMRI to achieve maximal, safe adenoma resection.
\end{abstract}

http://thejns.org/doi/abs/10.3171/2015.12.FOCUS15564

KEY WORDS intraoperative MRI; pituitary adenoma; endoscopy; volumetry; transsphenoidal surgery

$\Lambda$ LTHOUGH pituitary adenomas (PAs) are commonly classified as benign lesions, their clinical course is not always benign, and studies have confirmed that patients harboring a secreting adenoma have a reduced life expectancy, particularly those affected by adrenocorticotropic hormone (ACTH)- or growth hormone $(\mathrm{GH})-$ secreting adenoma. ${ }^{15,24,29,38,46}$ For such patients, endocrinological remission through gross-total resection (GTR) is the goal. Similarly, GTR is recommended for nonfunctioning pituitary adenomas (NFAs) requiring surgery, since subtotal resection (STR) and adenoma remnants after surgery have been repeatedly shown to represent a risk factor

ABBREVIATIONS ACTH = adrenocorticotropic hormone; EOR = extent of resection; $\mathrm{GH}=$ growth hormone; GTR = gross-total resection; iMRI = intraoperative MRI; NFA = nonfunctioning pituitary adenoma; $\mathrm{PA}=$ pituitary adenoma; $\mathrm{STR}$ = subtotal resection; $\mathrm{t}$ = targeted; TSS = transsphenoidal surgery; TVDT = tumor volume doubling time. SUBMITTED October 31, 2015. ACCEPTED December 28, 2015. INCLUDE WHEN CITING DOI: 10.3171/2015.12.FOCUS15564. 
for adenoma regrowth ${ }^{8,20,31,35}$ and possibly a reduced life expectancy. ${ }^{10}$ Therefore, intraoperative technical aids to increase the extent of resection (EOR) of PAs continue to attract a lot of attention in the neurosurgical and endocrinological communities.

Surgical techniques for PAs include the sublabial submucosal, the transseptal, and the endonasal approaches. In 1992 the endonasal endoscopic approach was first described $^{26}$ and gained wide popularity in the neurosurgical community because of its increased intraoperative viewing capacity and possibly improved GTR rate. Contrastenhanced intraoperative MRI (iMRI), first introduced by Black et al. in $1994,{ }^{6}$ has been increasingly used in pituitary surgery based on the assumption that it would improve GTR rates. ${ }^{14,17,21,33,34,36,37,41,47,48}$ Moreover, it has been stated that iMRI may be helpful even in patients in whom GTR is not feasible. ${ }^{34}$ In these patients, iMRI could still help to extend the tumor resection beyond the capabilities of microsurgical or endoscopic techniques alone. Lastly, some authors have suggested that iMRI can reduce the incidence of intrasellar remnants. ${ }^{11}$ Intrasellar adenoma remnants are amenable to complete and safe resection as long as they can be correctly detected. The rate of intrasellar adenoma remnants may, therefore, be considered a reliable surrogate marker of the surgical result.

All reports on the adjunctive benefit of iMRI have so far based their claims on qualitative analysis alone and not on quantitative volumetric measurement data. Furthermore, imaging of the sellar region is highly dependent on the technical performance of the scanner. Only a few reports have analyzed the added value of high-field iMRI, and even fewer reports have described the value of 3-T intraoperative MRI (3T-iMRI) in PA surgery. The aims of the present study were 1) to present the surgical results obtained with 3T-iMRI in a consecutive series of patients who underwent endoscopic transsphenoidal surgery (TSS) for PA, and 2) to report quantitative volumetric measurements of the EOR for both the whole adenoma and, more specifically, the intrasellar adenoma component.

\section{Methods \\ Patients}

Clinical and radiological data on patients who underwent surgery for PA between July 2013 and June 2015 at the Department of Neurosurgery, University Hospital of Zürich, were prospectively collected and retrospectively analyzed. All patients were treated according to the same PA protocol, and all had a complete endocrinological assessment preoperatively and immediately postoperatively as well as 6 weeks and 3 months postoperatively. Ophthalmological assessment, including testing of visual function and visual field, was routinely performed before and after surgery. Patient data were treated according to the ethical standards of the Declaration of Helsinki as approved by our institutional committee (Cantonal Ethics Committee Zürich).

\section{Neuroimaging and Volumetric Measurement}

All patients underwent preoperative, intraoperative, and 3-month postoperative volumetric contrast-enhanced 3T-MRI (Siemens 3-T Skyra VD13 with a NORAS MRI
Products intraoperative 8-channel head coil). Adenoma morphology was graded according to the $\mathrm{Knosp}^{27}$ and Hardy classifications. ${ }^{52}$ Source DICOM images of the volumetric sequences of each 3-T MR image (pre-, intra-, and postoperative) were uploaded onto iPlan software for volumetric measurements (iPlan Cranial, BrainLab) for each patient. Each adenoma was manually contoured on source images to allow subsequent 3D rendering and volumetric measurement through the software (Fig. 1). Extent of resection was measured on both intraoperative and 3-month postoperative MRI and was calculated as follows: 1) final $\mathrm{EOR}=$ percentage of residual tumor at the 3-month MRI compared with tumor on preoperative MRI; 2) endoscopic EOR $=$ percentage of residual tumor at the 3T-iMRI compared with tumor on preoperative MRI; and 3) iMRI EOR $=$ percentage of residual tumor at the postoperative MRI compared with tumor on 3T-iMRI, to measure the contribution of 3T-iMRI in improving the EOR. Mean differences between EORs among groups were tested with the paired-sampled Student t-test (or ANOVA for multiple comparisons). The null hypothesis was that there was no difference in the average EOR before (endoscopic EOR) and after 3T-iMR (final EOR). Correlations among continuous variables were studied with the Pearson test. For descriptive statistics, the cohort was divided into 2 groups: targeted (t)GTR, in which GTR was the goal of surgery; and targeted subtotal resection (tSTR), in which GTR was deemed not possible because of adenoma extension, and therefore only STR was the goal. The decision about the surgical goal for each adenoma was made based on the invasiveness pattern and was registered in the database; adenomas classified as Knosp Grade 0, 1, or 2 were considered for GTR.

\section{Surgical Procedure and Intraoperative Imaging}

The 3T-iMRI suite consists of a 2-room concept in which the patient is moved and the MR scanner remains fixed. The operating theater is connected to the MRI suite by a sliding door. All surgical procedures were performed by the same surgical team consisting of a neurosurgeon (L.R.) and an otorhinolaryngologist (D.H.) and following the same surgical protocol described as follows. A standard endonasal transsphenoidal endoscopic (Storz) approach with the common 3-hand technique was performed; a mononostril approach was used in $90 \%$ of the patients. The surgical goal (tGTR vs tSTR) was decided before surgery, as described above. After the neurosurgeon declared that the resection was complete or felt that further resection was not safe enough, the surgery was interrupted and 3T-iMRI was performed. When 3T-iMRI confirmed GTR, the surgery was completed with a sellar reconstruction. When the 3T-iMRI showed residual tumor, further endoscopic inspection was done and additional resection was performed if feasible. Intrasellar remnants were always considered to be amenable to further resection. Only 1 3T-iMRI session was performed for each patient.

\section{Results}

Fifty consecutive patients ( 23 females and 27 males, mean age of 52 years [range 21-83 years]) underwent 51 


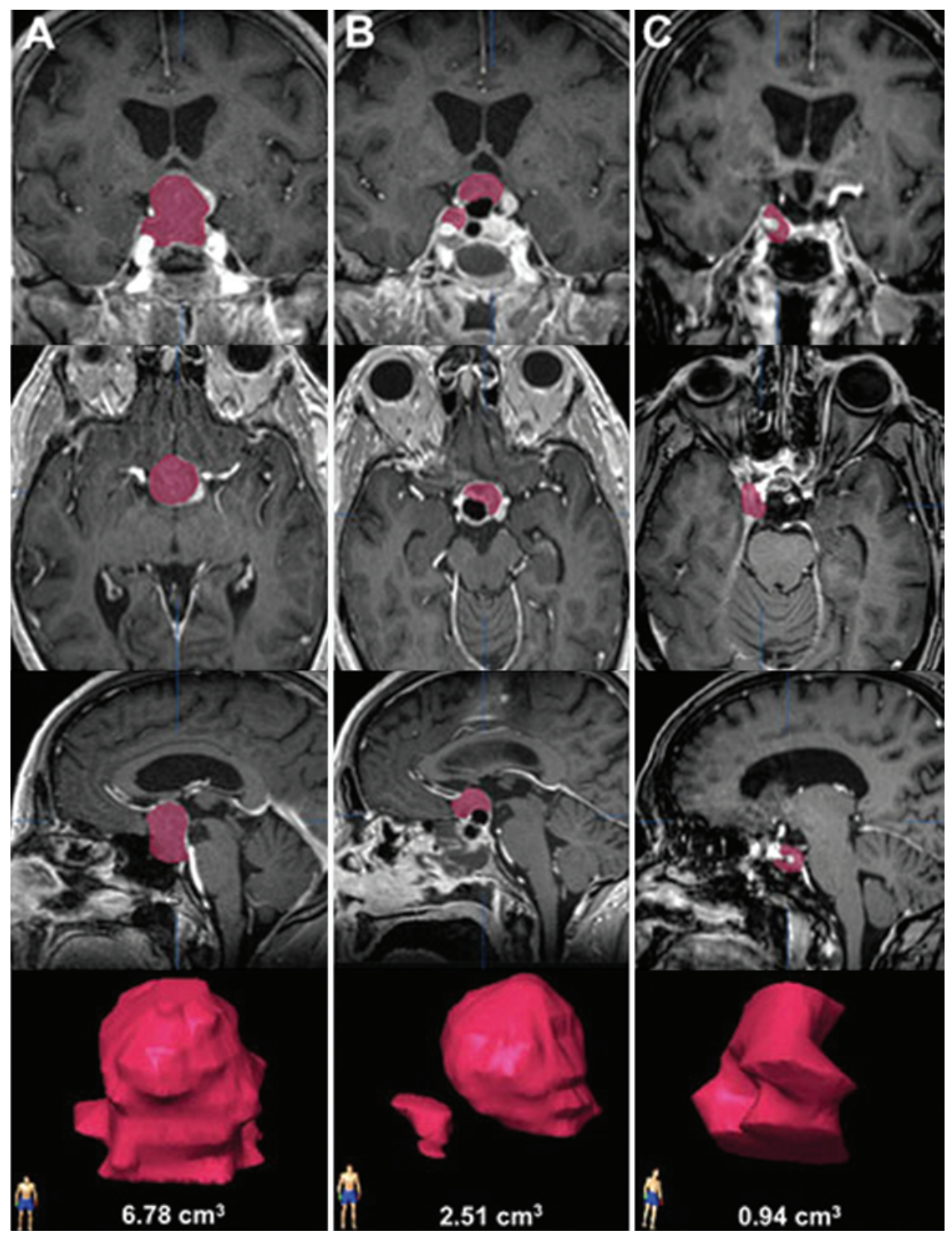

FIG. 1. Volumetric segmentation of adenoma volume on the preoperative (A), intraoperative (B), and postoperative (C) MRI.

operations in the study period. Thirty-three patients $(66 \%)$ harbored NFA and 17 (34\%) had functioning adenoma; 9 patients (10 operations) had a GH-secreting adenoma, 7 had treatment-refractory prolactinoma, and 1 had an ACTH-secreting adenoma (Table 1). Average volume of the surgically treated adenomas was $5.23 \mathrm{~cm}^{3}$ (range 0.09 $22.14 \mathrm{~cm}^{3}$, median volume $3.10 \mathrm{~cm}^{3}$ ), and mean adenoma diameter was $21.1 \mathrm{~mm}$ (range 5-47 mm). Average volume for the NFAs was $6.60 \mathrm{~cm}^{3}$ (range $0.56-22.14 \mathrm{~cm}^{3}$, median $4.60 \mathrm{~cm}^{3}$ ), whereas for the functioning adenomas it was $2.72 \mathrm{~cm}^{3}$ (range $0.09-20.60 \mathrm{~cm}^{3}$, median $0.92 \mathrm{~cm}^{3}$ ).

\section{Resection Results}

Thirty-four PAs were in the tGTR group and 17 in the tSTR group (Fig. 2). For the entire cohort, GTR was achieved in 31 of 51 operations, corresponding to a GTR rate of $61 \%$, and the average EOR was $95 \%$ at the 3-month postoperative MRI. More specifically, in the tGTR group, GTR was indeed achieved in 30 (88\%) of 34 operations. Gross-total resection was also achieved in 1 of the 17 tSTRs. Average overall EOR was $99 \%$ and $86 \%$ for the tGTR and tSTR groups, respectively, at 3 months after surgery. Surgical complications were as follows. Minor infections occurred in 2 patients (pneumonia in 1 and sphenoidal sinusitis in 1), whereas 1 patient (2\%) had meningitis as a consequence of a CSF leak. Cerebrospinal fluid leak requiring surgery occurred in 3 patients $(6 \%)$, and endocrine function deteriorated in 5 patients (hypothyroidism [1], permanent diabetes insipidus [1], new hypocortisolism [2], hypogonadism [1]). Of the 17 patients with a 
TABLE 1. Summary of volumetric resection results and remnant locations before and after 3T-iMR

\begin{tabular}{|c|c|c|c|c|c|c|c|c|c|c|}
\hline $\begin{array}{l}\text { Case } \\
\text { No. }\end{array}$ & $\begin{array}{l}\text { Intended } \\
\text { Resection }\end{array}$ & $\begin{array}{l}\text { Knosp } \\
\text { Grade }\end{array}$ & $\begin{array}{l}\text { Hardy } \\
\text { Grade }\end{array}$ & $\begin{array}{l}\text { EOR at } \\
\text { 3T-iMR }\end{array}$ & $\begin{array}{l}\text { Remnant Location } \\
\text { at 3T-iMR }\end{array}$ & $\begin{array}{c}\text { EOR at } \\
\text { 3-Mo MRI }\end{array}$ & $\begin{array}{c}\text { Remnant } \\
\text { Location at 3-Mo } \\
\text { MRI }\end{array}$ & $\begin{array}{l}\text { New Endocrine } \\
\text { Deficit }\end{array}$ & $\begin{array}{l}\text { Endocrine } \\
\text { Remission }\end{array}$ & $\begin{array}{l}\text { Adenoma } \\
\text { Type }\end{array}$ \\
\hline 1 & tGTR & 1 & BII & 0.85 & IS, SS & 0.96 & IS & No & NA & NFA \\
\hline 2 & tGTR & 2 & All & 0.70 & IS & 1.00 & - & No & Yes & $\mathrm{GH}$ \\
\hline 3 & tGTR & 2 & BIII & 1.00 & - & 1.00 & - & Yes & NA & NFA \\
\hline 4 & tGTR & 0 & All & 1.00 & - & 1.00 & - & No & No & PRL \\
\hline 5 & tGTR & 0 & 01 & 1.00 & - & 1.00 & - & No & Yes & $\mathrm{GH}$ \\
\hline 6 & tGTR & 2 & Bll & 0.95 & IS & 1.00 & - & No & NA & NFA \\
\hline 7 & tGTR & 0 & 01 & 1.00 & - & 1.00 & - & No & Yes & PRL \\
\hline 8 & tGTR & 2 & All & 1.00 & - & 1.00 & - & No & NA & NFA \\
\hline 9 & tGTR & 2 & AIV & 1.00 & - & 1.00 & - & No & NA & NFA \\
\hline 10 & tGTR & 2 & All & 1.00 & - & 1.00 & - & No & NA & NFA \\
\hline 11 & tGTR & 0 & 01 & 1.00 & - & 1.00 & - & No & Yes & PRL \\
\hline 12 & tGTR & 2 & All & 1.00 & - & 1.00 & - & No & NA & NFA \\
\hline 13 & tGTR & 0 & 01 & 0.53 & IS & 0.83 & IS & No & No & PRL \\
\hline 14 & tGTR & 0 & 0l & 1.00 & - & 1.00 & - & No & Yes & PRL \\
\hline 15 & tGTR & 2 & Oll & 1.00 & $S^{*}$ & 1.00 & - & No & NA & NFA \\
\hline 16 & tGTR & 2 & All & 1.00 & - & 1.00 & - & No & NA & NFA \\
\hline 17 & tGTR & 1 & All & 1.00 & - & 1.00 & - & No & Yes & $\mathrm{GH}$ \\
\hline 18 & tGTR & 1 & BIV & 0.88 & IS, CS & 0.97 & IS & No & NA & NFA \\
\hline 19 & tGTR & 0 & 이 & 0.80 & IS & 1.00 & - & No & Yes & $\mathrm{GH}$ \\
\hline 20 & tGTR & 2 & AIV & 0.94 & SS & 1.00 & - & No & NA & NFA \\
\hline 21 & tGTR & 1 & $\mathrm{Cll}$ & 0.96 & IS & 1.00 & - & No & NA & NFA \\
\hline 22 & tGTR & 2 & CIII & 0.92 & IS, SS & 1.00 & - & No & NA & NFA \\
\hline 23 & tGTR & 0 & Alll & 0.74 & IS, SS & 1.00 & - & No & NA & NFA \\
\hline 24 & tGTR & 1 & Alll & 0.97 & IS & 1.00 & - & No & NA & NFA \\
\hline 25 & tGTR & 0 & 이 & 1.00 & - & 1.00 & - & Yes & Yes & ACTH \\
\hline 26 & tGTR & 1 & BII & 0.98 & IS & 1.00 & - & No & NA & NFA \\
\hline 27 & tGTR & 1 & 이 & 0.88 & IS & 1.00 & - & No & Yes & PRL \\
\hline 28 & tGTR & 2 & AIV & 1.00 & - & 1.00 & - & No & NA & NFA \\
\hline 29 & tGTR & 2 & BIV & 0.96 & SS & 1.00 & - & No & NA & NFA \\
\hline 30 & tGTR & 2 & BIV & 0.95 & IS & 1.00 & - & No & No & $\mathrm{GH}$ \\
\hline 31 & tGTR & 3 & NA & 0.20 & CS & 1.00 & - & No & NA & NFA \\
\hline 32 & tGTR & 2 & All & 0.96 & SS & 1.00 & - & Yes & NA & NFA \\
\hline 33 & tGTR & 1 & 011 & 1.00 & - & 1.00 & - & No & No & $\mathrm{GH}$ \\
\hline 34 & tGTR & 2 & CIV & 0.94 & IS, SS & 0.99 & IS & No & NA & NFA \\
\hline 35 & tSTR & 4 & CIV & 0.63 & CS, SS & 0.86 & CS, SS & No & NA & NFA \\
\hline 36 & tSTR & 3 & Alll & 0.76 & IS, CS, SS & 0.94 & CS & No & NA & NFA \\
\hline 37 & tSTR & 3 & All & 0.91 & IS, CS & 0.99 & CS & Yes & Yes & $\mathrm{GH}$ \\
\hline 38 & tSTR & 3 & AIV & 0.89 & IS, CS & 0.91 & CS & No & NA & NFA \\
\hline 39 & tSTR & 3 & CIV & 0.84 & CS, SS & 0.84 & CS, SS & No & NA & NFA \\
\hline 40 & tSTR & 4 & DIV & 0.50 & CS, RS & 0.50 & CS, RS & No & NA & NFA \\
\hline 41 & tSTR & 3 & DIV & 0.24 & CS, SS & 0.24 & CS, SS & No & NA & NFA \\
\hline 42 & tSTR & 3 & BII & 0.94 & IS, SS & 0.97 & SS & No & NA & NFA \\
\hline 43 & tSTR & 3 & All & 0.95 & $-\dagger$ & 0.95 & CS & No & NA & NFA \\
\hline 44 & tSTR & 3 & AIV & 0.90 & CS & 0.90 & CS & No & No & $\mathrm{GH}$ \\
\hline 45 & tSTR & 3 & BII & 0.96 & SS & 1.00 & - & No & NA & NFA \\
\hline 46 & tSTR & 2 & BIV & 0.89 & IS & 0.89 & IS & Yes & No & PRL \\
\hline 47 & tSTR & 4 & BIV & 0.94 & CS, SS & 0.94 & CS, SS & No & NA & NFA \\
\hline
\end{tabular}


» CONTINUED FROM PAGE 4

TABLE 1. Summary of volumetric resection results and remnant locations before and after 3T-iMR

\begin{tabular}{|c|c|c|c|c|c|c|c|c|c|c|}
\hline $\begin{array}{l}\text { Case } \\
\text { No. }\end{array}$ & $\begin{array}{l}\text { Intended } \\
\text { Resection }\end{array}$ & $\begin{array}{l}\text { Knosp } \\
\text { Grade }\end{array}$ & $\begin{array}{l}\text { Hardy } \\
\text { Grade }\end{array}$ & $\begin{array}{l}\text { EOR at } \\
\text { 3T-iMR }\end{array}$ & $\begin{array}{c}\text { Remnant Location } \\
\text { at } 3 \text { T-iMR }\end{array}$ & $\begin{array}{c}\text { EOR at } \\
\text { 3-Mo MRI }\end{array}$ & $\begin{array}{c}\text { Remnant } \\
\text { Location at 3-Mo } \\
\text { MRI }\end{array}$ & $\begin{array}{c}\text { New Endocrine } \\
\text { Deficit }\end{array}$ & $\begin{array}{l}\text { Endocrine } \\
\text { Remission }\end{array}$ & $\begin{array}{c}\text { Adenoma } \\
\text { Type }\end{array}$ \\
\hline 48 & tSTR & 3 & All & 0.53 & IS, CS & 0.70 & CS & No & No & $\mathrm{GH}$ \\
\hline 49 & tSTR & 0 & CIII & 0.75 & SS & 0.98 & SS & Lost & Lost & NFA \\
\hline 50 & tSTR & 3 & CIV & 0.74 & CS, SS & 0.96 & CS & No & NA & NFA \\
\hline 51 & tSTR & 4 & BIV & 0.97 & CS & 0.97 & CS & No & No & $\mathrm{GH}$ \\
\hline
\end{tabular}

CS = cavernous sinus; IS = intrasellar; $\mathrm{NA}=$ not applicable; $\mathrm{PRL}=$ prolactin; $\mathrm{RS}=$ retrosellar; $\mathrm{SS}=$ suprasellar.

* False positive.

$\dagger$ False negative.

functioning adenoma, GTR was achieved in 11 and complete endocrinological remissions occurred in 10 of them (GH-secreting adenoma in 5, prolactin-secreting adenoma in 4, and ACTH-secreting adenoma in 1). No patient experienced deterioration of the visual field or visual acuity.

\section{Influence of IMRI on GTR and EOR}

Details on how the use of 3T-iMRI influenced the course of surgery are reported in Fig. 2. In the tGTR group, GTR increased from $16(47 \%)$ of 34 to $30(88 \%)$ of 34 and EOR from $91 \%$ at 3T-iMRI to $99 \%$ at the 3 -month MRI $(\mathrm{p}<0.05)$. In the tSTR group, GTR could be achieved in $1(6 \%)$ of 17 cases after 3T-iMRI. More noticeably, EOR increased in the tSTR group from 79\% to $86 \%$ ( $p<0.05$ ). Overall, the use of 3T-iMRI led to further resection in 27 (53\%) of 51 cases, and GTR was achieved in $15(56 \%)$ of these 27 cases. Thus, the GTR rate for the entire cohort increased from $31 \%$ (16 of 51 cases) to $61 \%$ ( 31 of 51 cases) and the EOR increased from $87 \%$ to $95 \%(\mathrm{p}<0.05)$. The amount of adjunctive EOR due to 3T-iMR did not show any relationship with adenoma functional activity $(\mathrm{p}=$ $0.76)$, Knosp classification ( $\mathrm{p}=0.48$ ), Hardy classification $(\mathrm{p}=0.36)$, initial tumor volume $(\mathrm{p}=0.23)$, or adenoma diameter $(\mathrm{p}=0.51)$.

There were 1 false-positive and 1 false-negative findings. In 1 patient (Case 43), no remnants could be seen at 3T-iMRI; therefore, no further resection was undertaken. However, a small residual tumor $\left(0.19 \mathrm{~cm}^{3}\right)$ was detected in the left cavernous sinus at 3-month postoperative MRI. In another patient (Case 15), a small suprasellar remnant adenoma was suspected on 3T-iMRI, but it could not be confirmed either intraoperatively, despite further inspection, or at the 3-month postoperative MRI.

\section{Location of Adenoma Remnants}

Detailed description of the location of adenoma remnants is provided in Table 1. Overall, adenoma remnants were seen in 36 cases at the 3T-iMRI. Intrasellar adenoma remnants were detected at 3T-iMRI in 20 cases (39\%) either alone or in combination with an adenoma remnant in other locations (suprasellar, cavernous sinus, retrosellar). At the 3-month postoperative MRI follow-up, intrasellar remnants were visible in only 5 patients (10\%), resulting in a $90 \%$ GTR rate (46 of 51 cases) of the intrasellar adenoma in the entire cohort. The difference in the number of ade- noma remnants between 3T-iMRI and 3-month postoperative MRI was statistically significant (chi-square $=0.007$ ). The volumes of the 5 intrasellar remnants were always tiny and averaged $0.21 \mathrm{~cm}^{3}$ (median $0.15 \mathrm{~cm}^{3}$, range $0.03-0.63$ $\mathrm{cm}^{3}$ ). In the remaining 15 cases with residual adenoma at the 3-month follow-up, remnants were in the cavernous sinus alone in 8 , the cavernous sinus and suprasellar cisterns in 4 , and the cavernous sinus and retrosellar region in 1. Purely suprasellar remnants were visible in 2 cases.

\section{Discussion \\ Resection Results}

Since its introduction in 1994, endoscopy has been increasingly used for transsphenoidal resection of PA with excellent results. Reported GTR rates range between $44 \%{ }^{44}$ and $88 \% .^{12}$ In series adopting endoscopy and iMRI, GTR rates achieved at the iMRI have been reported to be much lower, ranging from as low as $34 \%$ and $41 \% \%^{7,19,48}$ to as high as $62 \% .^{3}$ Indeed, a literature review suggests that groups adopting intraoperative imaging tend to have relatively lower rates of initial GTR before performing iMRI than groups who do not use any intraoperative imaging. We thus performed a PubMed and Scopus search (search terms "intraoperative," "MR," "pituitary") and selected those studies expressly reporting the number of patients harboring a tumor remnant at iMRI. From the 24 studies selected, ${ }^{1-3,3,14,16,17,19,22,28,32-34,36,37,40,41,43,45,47,48,50,51,53}$ we pooled the GTR data at the moment of iMRI. The average initial GTR rate was $51 \%$, which compares poorly to rates achieved in both pure endoscopic and pure microsurgical series as reported in a recent meta-analysis $(79 \%$ and $65 \%$, respectively $\left.{ }^{13}\right)$. However, after pooling the final GTR rate of all the above-mentioned iMRI studies, we calculated a GTR rate of $73 \%$. These data are comparable to and eventually in line with the best GTR achievable with endoscopy and microsurgery alone. Our GTR rates, 61\% in the whole cohort and $88 \%$ in tGTR group, are in line and even compare favorably with rates in the literature if we consider only the tGTR group.

The use of iMRI for pituitary surgery is the subject of animated debate in the neurosurgical community not lastly given its high acquisition, installation, and operation costs and prolonged operation times when used. Moreover, several authors continue to express skepticism toward its effectiveness and note-mainly in commentaries to iMRI papers (for example, see Powell in Paternó et al., ${ }^{37}$ Kelly in 


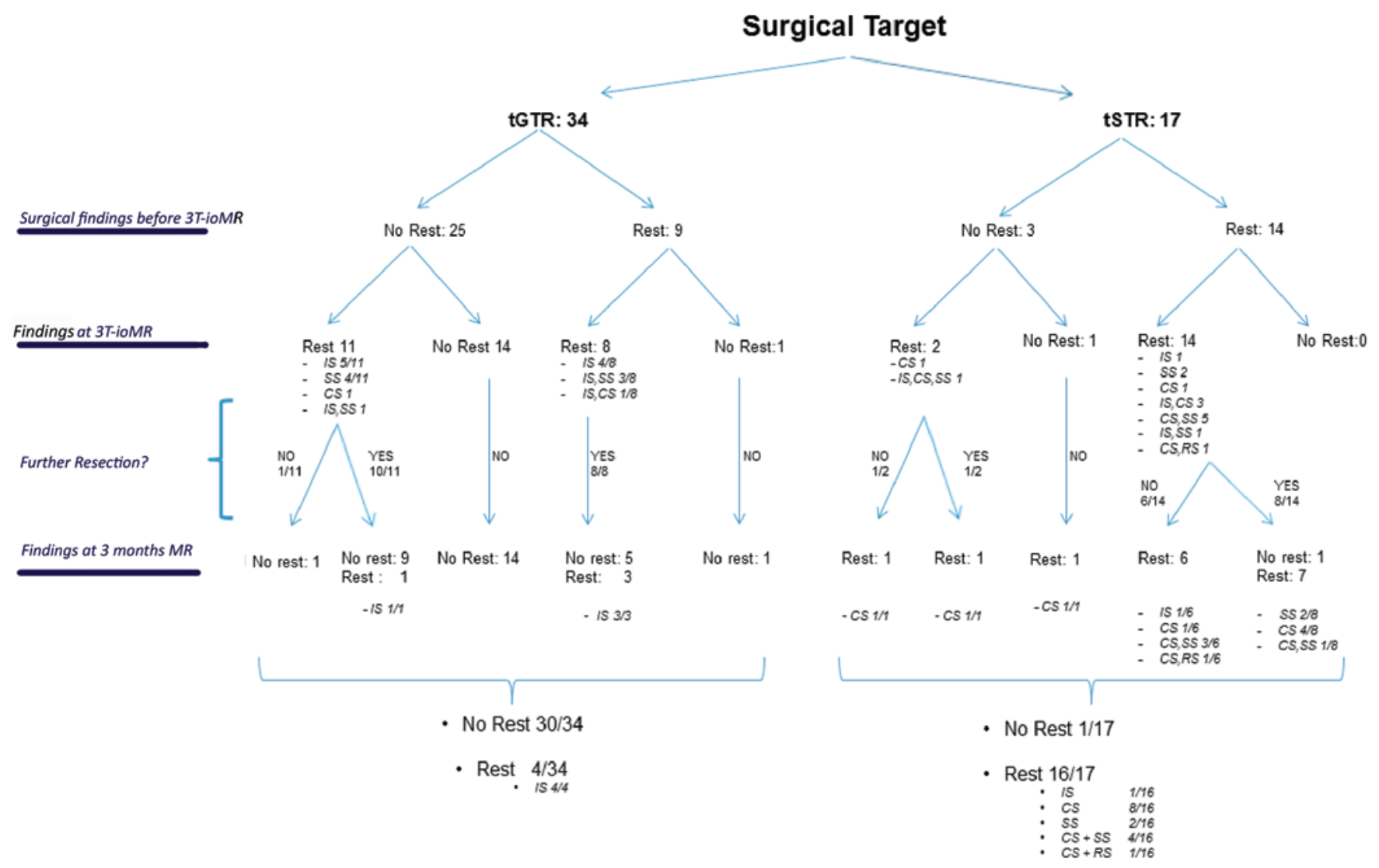

FIG. 2. Schematic of the impact of $3 \mathrm{~T}$-iMR in pituitary endoscopic surgery. CS = cavernous sinus; IS = intrasellar; Rest = remnant; $\mathrm{RS}=$ retrosellar; $\mathrm{SS}=$ suprasellar; $3 \mathrm{~T}$-ioMR = 3-T intraoperative MR.

Schwartz et al., ${ }^{43}$ Barnett in Gerlach et al., ${ }^{19}$ and Mayberg in Wu et al..$^{53}$ - that the use of iMRI biases the surgeon who, knowing that he or she will perform iMRI, would tend to be less aggressive in the pre-iMRI phase of the surgery than he or she would if the iMRI were unavailable. Given our experience, we tend to agree with this line of thinking. Furthermore, Powell ${ }^{39}$ stated that iMRI would simply show predictable remnants, which although rendered visible by iMRI are not resectable. This would explain the similarity of the GTR rates achieved among the different surgical techniques-microsurgery and endoscopy, with or without iMRI.

It is difficult to make a meaningful comparison of GTR rates among heterogeneous patient series in which the percentage of patients with different surgical goals can vary (tGTR vs tSTR), and often outcome assessment (low-field vs high-field MRI) can also vary considerably. Still, most authors have reported that iMRI increases the EOR in adenoma surgery, especially for the tSTR group of patients. ${ }^{4,533,34,41}$ This suggests that although GTR rates appear similar among the different series, regardless of the technique adopted, the EOR is more extensive with the use of iMRI. Nevertheless, a quantitative study analyzing volumetric measurements of both EOR and volume remnants after 3T-iMRI has not been published so far.

\section{Volumetric Quantification of the Role of 3T-iMRI}

Residual adenoma has been reported as a risk factor for regrowth in several studies, ${ }^{4,8,10,18,20,30}$ In a retrospective study on NFAs in 2008, Chang and coworkers ${ }^{10}$ found a recurrence rate of $10 \%$ in a cohort of 663 patients with a median follow-up of 8.4 years. Predictive factors for recurrence in that study were invasion of the cavernous sinus and subtotal resection without adjuvant radiotherapy. No predictive volumetric threshold was reported. According to Tanaka et al. ${ }^{49}$ and Honegger et al. ${ }^{25}$ recurrent adenomas show mostly an exponential growth pattern. However, tumor volume doubling time (TVDT) can vary significantly between cases, with a younger age being a possibly relevant risk factor. ${ }^{49}$ The MIB-1 index also seems to inversely correlate with TVDT. ${ }^{25,49}$ Whether an increase in the EOR plays a clinically relevant role in subtotally resected adenomas has not been established, however. Specifically, it is not known if stepwise incremental EOR values for adenomas correlate with incremental progression-free survival or whether the absolute residual volume or the relative residual volume is the prognostic factor. The answer, we hope, will come from large observational volumetric studies with long-term follow-ups. Similar studies are currently lacking in the literature, although some authors, particularly in radiosurgical series, have recently started to routinely assess the volumes of PAs and measure outcome in terms of EOR. ${ }^{11,23,31}$ Even though Class I evidence is lacking, we believe that in patients undergoing STR, the residual adenoma volume may be a prognostic factor, especially in young patients and in adenomas with 
high MIB-1 indexes. Therefore, maximal safe resection should be the surgical goal, always aiming for the smallest residual volume without adding any surgical or endocrinological morbidity, as in the strategy increasingly adopted for the treatment of gliomas. ${ }^{42}$ It is debatable, however, if removing additional tumor volume compensates for the potential risk of the higher morbidity associated with further surgical manipulation and with the prolonged surgical times due to the use of iMRI. This topic remains open for discussion. As a matter of fact, there is no clear evidence in the literature indicating that the use of iMRI in pituitary surgery leads to additional morbidity. It is known, as a general rule, that a longer surgery is associated with a higher incidence of complications, particularly if the surgery lasts more than 2 hours. ${ }^{9}$ In our study, however, we did not have any complications characteristically attributable to prolonged surgery, such as respiratory failure or deep venous thrombosis. It is also difficult to ascertain whether the postoperative occurrence of a new deficit is due to the surgical manipulation before or after the iMRI (this particularly concerns endocrinological deficits). In our series, no complication can be unequivocally attributed to further resection after 3T-iMRI, which is in line with findings in the available literature. Of the 3 patients who required surgical revision for rhinoliquorrhea, 1 had no intraoperative evidence of CSF loss, whereas the other 2 already had some CSF loss before 3T-iMRI was performed. Of the 5 patients with new postoperative endocrinological deficits, only 2 had further resection after 3T-iMRI.

Three-tesla iMRI allows very precise intraoperative assessment of the EOR and gives immediate feedback to the surgeon. In other words, it allows the surgeon not only to determine the presence or absence of a remnant and its precise location, but also to measure the residual volume. The surgeon can therefore adapt his or her surgical strategy to precise information and better evaluate the EOR that can be achieved and the risk the patient will incur by adopting a more aggressive strategy with further resection. The use of 3T-iMRI significantly helped in reaching this target and achieving the increase of $7 \%$ and $8 \%$ in the EOR, as reported in our tSTR and tGTR groups, respectively.

\section{Location of Adenoma Remnant}

The high-definition imaging quality achieved with 3TiMRI is such that residual adenoma parts can be finely depicted not only in the suprasellar space, as is the case with low-field iMRI, but also in the intra- and parasellar areas (Figs. 1 and 3). As stated above and confirmed by our data, accurate visualization of parasellar, particularly intracavernous, remnants does not usually imply that a GTR will be achieved. On the contrary, intrasellar remnants are mostly amenable to complete resection. In our opinion, for the intrasellar remnants in particular, improved intraoperative visualization with $3 \mathrm{~T}$-iMR is important so that resectable remnants are not overlooked. Indeed our data tend to support this belief since we had 21 (41\%) of 51 intrasellar remnants detected with 3T-iMR, as compared with only $5(10 \%)$ of 51 at the 3-month MRI follow-up. These intrasellar remnants were small, averaging $0.21 \mathrm{~cm}^{3}$. Similarly, Coburger et al. ${ }^{11}$ found a significantly lower incidence of intrasellar remnants in patients undergoing adenoma removal with the help of 1.5-T MRI compared with patients undergoing standard microsurgery (18\% vs 57\%). The very low rate of intrasellar remnants $(<10 \%)$ in our study tends to indicate that high-definition visualization of an intrasellar remnant with 3T-iMRI offers the opportunity to improve resection. The endoscope allows for accurate exploration of the sella and visualization of its contents. However, it does not allow one to "look behind," and in some cases adenoma tissue, even if in the field of view of the endoscope, cannot be reliably distinguished from pituitary parenchyma. Three-tesla iMRI helps not only to look behind, but also to discriminate between healthy pituitary and pathological adenoma tissue, offering a highly detailed anatomical view of the sella and its contents.
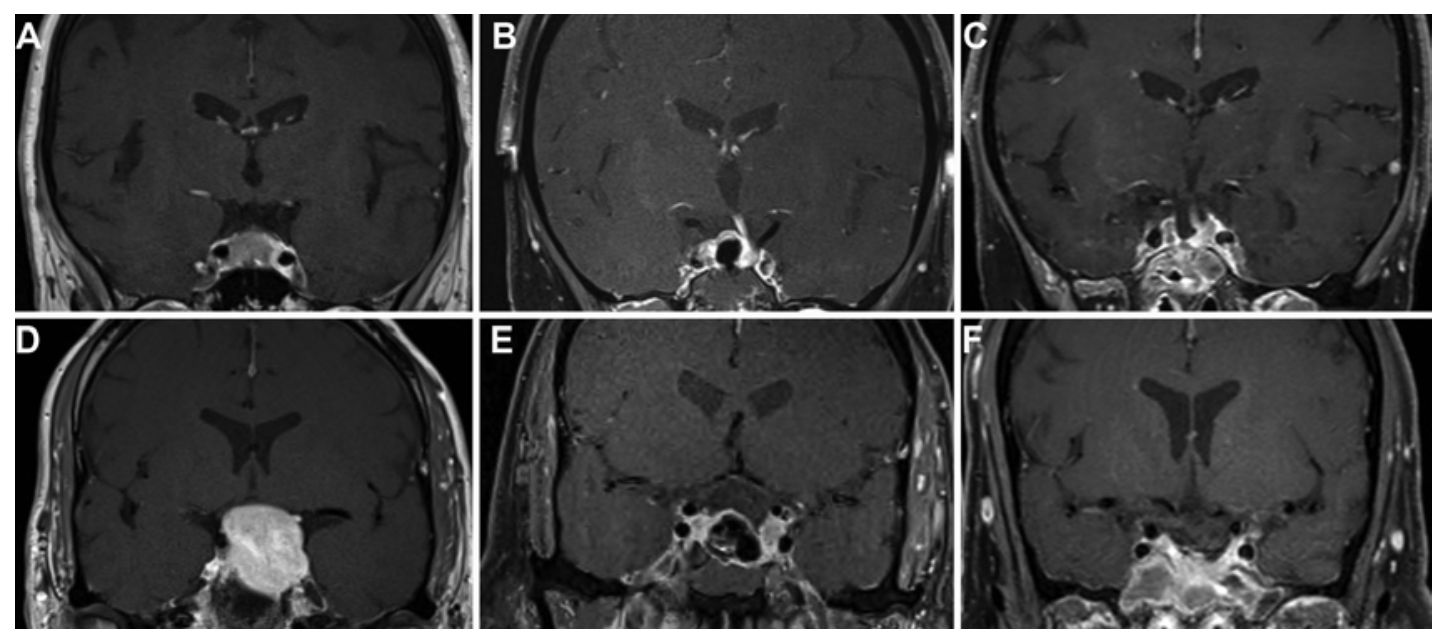

FIG. 3. Pre-, intra-, and postoperative imaging in 2 different cases. The intra- and parasellar compartments are finely depicted in both patients. Upper row: The intraoperative imaging clearly shows a small intrasellar rest on the right side, which could be further removed although not completely. Lower row: Some residual intrasellar remnants can be easily identified on the right side at the medial wall of the cavernous sinus. These were completely removed. 


\section{Conclusions}

With the use of 3T-iMRI, we achieved a GTR rate of $61 \%$ in the whole cohort and $88 \%$ in the tGTR group. The incorporation of 3T-iMRI helped to precisely determine the amount and location of residual tissue and to increase the EOR in both patient groups, tGTR (from 91\% to $99 \%$ ) and tSTR (from 79\% to 86\%). Moreover, it helped to achieve a very low rate of intrasellar remnants (10\%) in the entire cohort, showing that an intrasellar adenoma component is amenable to complete resection if it is correctly diagnosed during surgery. These data support the use of 3T-iMRI to help achieve maximal, safe adenoma resection.

\section{References}

1. Ahn JY, Jung JY, Kim J, Lee KS, Kim SH: How to overcome the limitations to determine the resection margin of pituitary tumours with low-field intra-operative MRI during transsphenoidal surgery: usefulness of Gadolinium-soaked cotton pledgets. Acta Neurochir (Wien) 150:763-771, 2008

2. Bellut D, Hlavica M, Schmid C, Bernays RL: Intraoperative magnetic resonance imaging-assisted transsphenoidal pituitary surgery in patients with acromegaly. Neurosurg Focus 29(4):E9, 2010

3. Berkmann S, Fandino J, Müller B, Remonda L, Landolt H: Intraoperative MRI and endocrinological outcome of transsphenoidal surgery for non-functioning pituitary adenoma. Acta Neurochir (Wien) 154:639-647, 2012

4. Berkmann S, Schlaffer S, Nimsky C, Fahlbusch R, Buchfelder M: Follow-up and long-term outcome of nonfunctioning pituitary adenoma operated by transsphenoidal surgery with intraoperative high-field magnetic resonance imaging. Acta Neurochir (Wien) 156:2233-2243, 2014

5. Berkmann S, Schlaffer S, Nimsky C, Fahlbusch R, Buchfelder M: Intraoperative high-field MRI for transsphenoidal reoperations of nonfunctioning pituitary adenoma. J Neurosurg 121:1166-1175, 2014

6. Black PM, Moriarty T, Alexander E III, Stieg P, Woodard EJ, Gleason PL, et al: Development and implementation of intraoperative magnetic resonance imaging and its neurosurgical applications. Neurosurgery 41:831-845, 1997

7. Bohinski RJ, Warnick RE, Gaskill-Shipley MF, Zuccarello M, van Loveren HR, Kormos DW, et al: Intraoperative magnetic resonance imaging to determine the extent of resection of pituitary macroadenomas during transsphenoidal microsurgery. Neurosurgery 49:1133-1144, 2001

8. Brochier S, Galland F, Kujas M, Parker F, Gaillard S, Raftopoulos $\mathrm{C}$, et al: Factors predicting relapse of nonfunctioning pituitary macroadenomas after neurosurgery: a study of 142 patients. Eur J Endocrinol 163:193-200, 2010

9. Canet J, Sabaté S, Mazo V, Gallart L, de Abreu MG, Belda J, et al: Development and validation of a score to predict postoperative respiratory failure in a multicentre European cohort: A prospective, observational study. Eur J Anaesthesiol 32:458-470, 2015

10. Chang EF, Zada G, Kim S, Lamborn KR, Quinones-Hinojosa A, Tyrrell JB, et al: Long-term recurrence and mortality after surgery and adjuvant radiotherapy for nonfunctional pituitary adenomas. J Neurosurg 108:736-745, 2008

11. Coburger J, König R, Seitz K, Bäzner U, Wirtz CR, Hlavac $\mathrm{M}$ : Determining the utility of intraoperative magnetic resonance imaging for transsphenoidal surgery: a retrospective study. J Neurosurg 120:346-356, 2014

12. Dehdashti AR, Ganna A, Karabatsou K, Gentili F: Pure endoscopic endonasal approach for pituitary adenomas: early surgical results in 200 patients and comparison with previous microsurgical series. Neurosurgery 62:1006-1017, 2008
13. DeKlotz TR, Chia SH, Lu W, Makambi KH, Aulisi E, Deeb Z: Meta-analysis of endoscopic versus sublabial pituitary surgery. Laryngoscope 122:511-518, 2012

14. Dort JC, Sutherland GR: Intraoperative magnetic resonance imaging for skull base surgery. Laryngoscope 111:15701575,2001

15. Etxabe J, Vazquez JA: Morbidity and mortality in Cushing's disease: an epidemiological approach. Clin Endocrinol (Oxf) 40:479-484, 1994

16. Fahlbusch R, Ganslandt O, Buchfelder M, Schott W, Nimsky $\mathrm{C}$ : Intraoperative magnetic resonance imaging during transsphenoidal surgery. J Neurosurg 95:381-390, 2001

17. Fahlbusch R, von Keller B, Ganslandt O, Kreutzer J, Nimsky $\mathrm{C}$ : Transsphenoidal surgery in acromegaly investigated by intraoperative high-field magnetic resonance imaging. Eur J Endocrinol 153:239-248, 2005

18. Ferrante E, Ferraroni M, Castrignanò T, Menicatti L, Anagni M, Reimondo G, et al: Non-functioning pituitary adenoma database: a useful resource to improve the clinical management of pituitary tumors. Eur J Endocrinol 155:823-829, 2006

19. Gerlach R, du Mesnil de Rochemont R, Gasser T, Marquardt G, Reusch J, Imoehl L, et al: Feasibility of Polestar N20, an ultra-low-field intraoperative magnetic resonance imaging system in resection control of pituitary macroadenomas: lessons learned from the first 40 cases. Neurosurgery 63:272285, 2008

20. Greenman Y, Ouaknine G, Veshchev I, Reider-Groswasser II, Segev Y, Stern N: Postoperative surveillance of clinically nonfunctioning pituitary macroadenomas: markers of tumour quiescence and regrowth. Clin Endocrinol (Oxf) 58:763769, 2003

21. Hall WA, Galicich W, Bergman T, Truwit CL: 3-Tesla intraoperative MR imaging for neurosurgery. J Neurooncol 77:297-303, 2006

22. Hlavica M, Bellut D, Lemm D, Schmid C, Bernays RL: Impact of ultra-low-field intraoperative magnetic resonance imaging on extent of resection and frequency of tumor recurrence in 104 surgically treated nonfunctioning pituitary adenomas. World Neurosurg 79:99-109, 2013

23. Hofstetter CP, Nanaszko MJ, Mubita LL, Tsiouris J, Anand VK, Schwartz TH: Volumetric classification of pituitary macroadenomas predicts outcome and morbidity following endoscopic endonasal transsphenoidal surgery. Pituitary 15:450-463, 2012

24. Holdaway IM, Bolland MJ, Gamble GD: A meta-analysis of the effect of lowering serum levels of GH and IGF-I on mortality in acromegaly. Eur J Endocrinol 159:89-95, 2008

25. Honegger J, Zimmermann S, Psaras T, Petrick M, Mittelbronn M, Ernemann U, et al: Growth modelling of non-functioning pituitary adenomas in patients referred for surgery. Eur J Endocrinol 158:287-294, 2008

26. Jankowski R, Auque J, Simon C, Marchal JC, Hepner H, Wayoff M: Endoscopic pituitary tumor surgery. Laryngoscope 102:198-202, 1992

27. Knosp E, Steiner E, Kitz K, Matula C: Pituitary adenomas with invasion of the cavernous sinus space: a magnetic resonance imaging classification compared with surgical findings. Neurosurgery 33:610-618, 1993

28. Lang MJ, Kelly JJ, Sutherland GR: A moveable 3-Tesla intraoperative magnetic resonance imaging system. Neurosurgery 68 (1 Suppl Operative):168-179, 2011

29. Lindholm J, Juul S, Jørgensen JO, Astrup J, Bjerre P, FeldtRasmussen U, et al: Incidence and late prognosis of Cushing's syndrome: a population-based study. J Clin Endocrinol Metab 86:117-123, 2001

30. Losa M, Mortini P, Barzaghi R, Ribotto P, Terreni MR, Marzoli SB, et al: Early results of surgery in patients with nonfunctioning pituitary adenoma and analysis of the risk of tumor recurrence. J Neurosurg 108:525-532, 2008 
31. Losa M, Valle M, Mortini P, Franzin A, da Passano CF, Cenzato M, et al: Gamma knife surgery for treatment of residual nonfunctioning pituitary adenomas after surgical debulking. J Neurosurg 100:438-444, 2004

32. Martin CH, Schwartz R, Jolesz F, Black PM: Transsphenoidal resection of pituitary adenomas in an intraoperative MRI unit. Pituitary 2:155-162, 1999

33. Netuka D, Masopust V, Belšán T, Kramář F, Beneš V: One year experience with 3.0 T intraoperative MRI in pituitary surgery. Acta Neurochir Suppl 109:157-159, 2011

34. Nimsky C, von Keller B, Ganslandt O, Fahlbusch R: Intraoperative high-field magnetic resonance imaging in transsphenoidal surgery of hormonally inactive pituitary macroadenomas. Neurosurgery 59:105-114, 2006

35. O'Sullivan EP, Woods C, Glynn N, Behan LA, Crowley R, O'Kelly P, et al: The natural history of surgically treated but radiotherapy-naïve nonfunctioning pituitary adenomas. Clin Endocrinol (Oxf) 71:709-714, 2009

36. Pamir MN: 3 T ioMRI: the Istanbul experience. Acta Neurochir Suppl 109:131-137, 2011

37. Paternó V, Fahlbusch R: High-Field iMRI in transsphenoidal pituitary adenoma surgery with special respect to typical localization of residual tumor. Acta Neurochir (Wien) 156:463-474, 2014

38. Plotz CM, Knowlton AI, Ragan C: The natural history of Cushing's syndrome. Am J Med 13:597-614, 1952

39. Powell M: The value of intra-operative MRI in trans-sphenoidal pituitary surgery. Acta Neurochir (Wien) 153:13751376, 2011

40. Qiu TM, Yao CJ, Wu JS, Pan ZG, Zhuang DX, Xu G, et al: Clinical experience of $3 \mathrm{~T}$ intraoperative magnetic resonance imaging integrated neurosurgical suite in Shanghai Huashan Hospital. Chin Med J (Engl) 125:4328-4333, 2012

41. Ramm-Pettersen J, Berg-Johnsen J, Hol PK, Roy S, Bollerslev J, Schreiner T, et al: Intra-operative MRI facilitates tumour resection during trans-sphenoidal surgery for pituitary adenomas. Acta Neurochir (Wien) 153:1367-1373, 2011

42. Sanai N, Polley MY, McDermott MW, Parsa AT, Berger MS: An extent of resection threshold for newly diagnosed glioblastomas. J Neurosurg 115:3-8, 2011

43. Schwartz TH, Stieg PE, Anand VK: Endoscopic transsphenoidal pituitary surgery with intraoperative magnetic resonance imaging. Neurosurgery 58 (1 Suppl):ONS44-ONS51, 2006

44. Sheehan MT, Atkinson JL, Kasperbauer JL, Erickson BJ, Nippoldt TB: Preliminary comparison of the endoscopic transnasal vs the sublabial transseptal approach for clinically nonfunctioning pituitary macroadenomas. Mayo Clin Proc 74:661-670, 1999

45. Steinmeier R, Fahlbusch R, Ganslandt O, Nimsky C, Buchfelder M, Kaus M, et al: Intraoperative magnetic resonance imaging with the Magnetom open scanner: concepts, neurosurgical indications, and procedures: a preliminary report. Neurosurgery 43:739-748, 1998

46. Sughrue ME, Chang EF, Gabriel RA, Aghi MK, Blevins LS:
Excess mortality for patients with residual disease following resection of pituitary adenomas. Pituitary 14:276-283, 2011

47. Sylvester PT, Evans JA, Zipfel GJ, Chole RA, Uppaluri R, Haughey BH, et al: Combined high-field intraoperative magnetic resonance imaging and endoscopy increase extent of resection and progression-free survival for pituitary adenomas. Pituitary 18:72-85, 2015

48. Szerlip NJ, Zhang YC, Placantonakis DG, Goldman M, Colevas KB, Rubin DG, et al: Transsphenoidal resection of sellar tumors using high-field intraoperative magnetic resonance imaging. Skull Base 21:223-232, 2011

49. Tanaka Y, Hongo K, Tada T, Sakai K, Kakizawa Y, Kobayashi S: Growth pattern and rate in residual nonfunctioning pituitary adenomas: correlations among tumor volume doubling time, patient age, and MIB-1 index. J Neurosurg 98:359-365, 2003

50. Tanei T, Nagatani T, Nakahara N, Watanabe T, Nishihata T, Nielsen ML, et al: Use of high-field intraoperative magnetic resonance imaging during endoscopic transsphenoidal surgery for functioning pituitary microadenomas and small adenomas located in the intrasellar region. Neurol Med Chir (Tokyo) 53:501-510, 2013

51. Theodosopoulos PV, Leach J, Kerr RG, Zimmer LA, Denny AM, Guthikonda B, et al: Maximizing the extent of tumor resection during transsphenoidal surgery for pituitary macroadenomas: can endoscopy replace intraoperative magnetic resonance imaging? J Neurosurg 112:736-743, 2010

52. Wilson CB: A decade of pituitary microsurgery. The Herbert Olivecrona lecture. J Neurosurg 61:814-833, 1984

53. Wu JS, Shou XF, Yao CJ, Wang YF, Zhuang DX, Mao Y, et al: Transsphenoidal pituitary macroadenomas resection guided by PoleStar N20 low-field intraoperative magnetic resonance imaging: comparison with early postoperative highfield magnetic resonance imaging. Neurosurgery 65:63-71, 2009

\section{Disclosures}

The authors report no conflict of interest concerning the materials or methods in this study or the findings specified in this paper.

\section{Author Contributions}

Conception and design: Serra, Regli. Acquisition of data: Serra, Burkhardt, Esposito, Pangalu, Valavanis, Holzmann, Schmid. Analysis and interpretation of data: Serra. Drafting the article: Serra, Regli. Critically revising the article: Bozinov, Pangalu, Holzmann, Schmid, Regli.

\section{Correspondence}

Carlo Serra, Department of Neurosurgery, Clinical Neuroscience Center, University Hospital of Zürich, University of Zürich, Frauenklinikstr 10, Zürich 8006, Switzerland. email: c.serra@ hotmail.it. 